NASA Technical Memorandum 100809

\title{
Service Offerings and Interfaces for the ACTS Network of Earth Stations
}

\author{
(AASA-TU-1008(9) SEEVICE CEFEEIAGS AND \\ I $\triangle T E R F A C E S$ FOE TEE ACTS NETHCER CF EARTH \\ STATICNS (NASA) $22 \mathrm{~F}$ CSCL OSF \\ N8 8-24663 \\ Unclas \\ $63 / 17 \quad 0149252$
}

Thom A. Coney

Lewis Research Center

Cleveland, Ohio

Prepared for the

12th International Communication Satellite Systems Conference

sponsored by the American Institute of Aeronautics and Astronautics

Arlington, Virginia, March 13-17, 1988 
SERVICE OFFERINGS AND INTERFACES FOR THE ACTS NETWORK OF EARTH STATIONS

\author{
Thom A. Coney \\ National Aeronautics and Space Administration \\ Lewis Research Center \\ Cleveland, Ohio 44135
}

\title{
SUMMARY
}

The Advanced Communications Technology Satellite (ACTS) is capable of two modes of communication. Mode 1 is a mesh network of Earth stations using baseband-switched, time-division multiple-access (BBS-TDMA) and hopping beams. Mode 2 is a mesh network using satellite-switched, time-division multipleaccess (SS-TDMA) and fixed (or hopping) beams.

The purposes of this paper is to present the functional requirements and the design of the ACTS Mode 1 Earth station terrestrial interface. Included among the requirements are that (1) the interface support standard telecommunications service offerings ( $1 . e .$, voice, video and data at rates ranging from $9.6 \mathrm{kbps}$ to $44 \mathrm{Mbps}$ ); (2) the interface support the unique design characteristics of the ACTS communications system (e.g., the real time demand assignment of satellite capacity); and (3) the interface support test hardware capable of validating ACTS communications processes. The resulting interface design makes use of an appropriate combination of $\mathrm{Tl}$ or T3 multiplexers and a small central office (maximum capacity 56 subscriber lines per unit).

\section{SERVICE OFFERINGS}

The NASA ACTS Project Office at NASA Lewis Research Center, Cleveland, Ohio, will acquire a number of Earth stations to operate as a Mode 1 network. This network of Earth stations will support two ACTS program objectives: to verify the technical performance of ACTS Mode 1 operation in geosynchronous orbit and to demonstrate the types and quallty of services that can be provided by an ACTS Mode 1 communications system. The terrestrial interface design is a critical element in assuring that these network Earth stations will meet the objectives. The following is a discussion of the applicable terrestrial interface design requirements, the resulting interface specifications, and the assoclated terrestrial input/output hardware. A functional block diagram of a network Earth station ( $f i g .1$ ).

\section{TERRESTRIAL INTERFACE DESIGN REQUIREMENTS}

\section{ACTS Mode I Telecommunications Services}

To enhance the likelihood of experimenter involvement with ACTS, the terrestrial interface must be easily integrated into existing communications plants. This means that the Earth station interface must be adaptable to the experimenter communications hardware and protocols, rather than vice versa. Therefore, three types of communications plants will be supported by the ACTS Mode 1 network and the network Earth station terrestrial interfaces: PBX's, key systems, and multiple subscriber lines. 
Assoclated with each plant type are a variety of standard telecommunications services and potential experiments. Within practical limits, the interface must support those services and experiments. Three categories of service will be offered with each of the above plant types (table 1). (This classification by data rate is done to simplify discussion only.) The first category of services is equivalent to today's terrestrial service offerings, as typified by analog voice and data rates of $\leq 56 \mathrm{kbit} / \mathrm{sec}$. The second category expands these services to include data rates of $\leq 1.536 \mathrm{Mbit} / \mathrm{sec}$ (the Tl rate is $1.544 \mathrm{Mbit} / \mathrm{sec}$, which includes $8 \mathrm{kHz}$ for framing and synchronization, leaving $1.536 \mathrm{Mbit} / \mathrm{sec}$ for user traffic) and $\mathrm{Tl}$ networking. The third category of services takes advantage of the advanced capabilities offered by ACTS. One of these advanced services emulates integrated services digital network (ISDN) processes in the Earth station interface and in the space segment. Another supports data rates in excess of $1.536 \mathrm{Mbit} / \mathrm{sec}$; e.g., compressed video at $3 \mathrm{Mbit} / \mathrm{sec}$ ( $T / \mathrm{C}$ ), $6 \mathrm{Mb} / \mathrm{t} / \mathrm{sec}$ (a T2 equivalent rate), and $44 \mathrm{Mblt} / \mathrm{sec}$. The first and second categories of service will be supported by all of the Mode 1 network Earth stations. The third category will be supported by the NASA Ground Station (NGS) and a small number of Earth stations, due to the limited availability of existing communications plant hardware employing these rates. In some cases, custom and/or nonstandard hardware will be required. The following discussion detalls these categories of service and describes how an Earth station will be integrated into the different types of communications plants.

\section{Category One Services}

As stated above, Mode 1 Earth stations will be placed on the premises and integrated into the communications plants of a variety of corporations, businesses, and universities. It is assumed that the various communications plants associated with these experimenters will vary widely in size and complexity. As stated previously, in order to accommodate the largest number of experimenters, three types of communications plants will be supported by the Category One (data rates $\leq 56 \mathrm{kbit} / \mathrm{sec}$ and analog voice) terrestrial interface. The large plant supported will be that using a private branch exchange (PBX); the medium plant supported will be that using a key system; and the small plant supported will be that using a number of subscriber lines.

For the system using a PBX, the Earth station interface will connect to the trunk side of the PBX using a duplex TI or a number of PBX trunks. This will require the addition of $T i$ multiplexing hardware within the PBX or, as a minimum, the addition of a number of PBX trunk lines to the output of the PBX. The PBX will also need to be programmed to recognize an access code labeling the PBX/Earth station trunks. Figure 2 illustrates these two methods of interconnecting the PBX to the Earth station. With either of these implementations, all of the telecommunications services avallable using the original plant and terrestrial links will be avallable using the Earth station and the ACTS satellite link. Specifically, this means that by dialing a one-digit ACTS access code, a two-digit destination Earth station ID, and the destination telephone number, an individual can make a phone call over. ACTS from any telephone in the plant to any distant telephone served by an Earth station. (If the ACTS access code is not dialed, the call will stay within the original plant and/or the terrestrial network.) The dialing sequence might be as follows: 
Dial 7 (PBX/Earth station trunk access code)

Dial 11 (destination Earth station ID)

Dial 433-3527 (destination handset address)

In addition to this voice traffic, all devices that presently use telephone circuits, e.g., FAX, computer terminals, slow scan video, etc., can operate in like manner over this satellite link. (Note: In some cases, bisynchronous-to-satelilite protocol adapters may be needed.)

The PBX/Earth station interface can also be used in a bypass mode ( $1 . e$. , to reach a telephone served by a destination plant's loca! central office and, thus, the distant local terrestrial network). Accomplishing this requires either a "leaky" PBX or an additional interface between the Earth station and the local central office $(\mathrm{CO})$. The latter interface is under consideration.

In order to support the middle size business office with Category One services, the Earth station interface must be compatible with a key system. The best way to interconnect the Earth station to the key system is to connect an unused trunk(s) directly to the Earth station interface. The key system control software would need to be modified, linking a specific button(s) on each hand set to the added trunk(s). Figure $3(a)$ illustrates this interface. To make a standard call in the terrestrial network, a caller selects a trunk connected directly to the local central office on the hand set. To make a call over the satellite network, a caller selects an "ACTS" trunk. In this case, the dialing sequence must include an Earth station identification number. As with the PBX interface, the plant telecommunications offerings remain unchanged, and the same service offerings become avallable over the satellite network.

If an unused trunk is not avallable in the key system, an interface to the Earth station can still be accomplished but in a much less transparent. manner. The method supported by the interface involves the routing of one or more of the existing trunks through the Earth station interface and then on to the local CO (fig. $3(b)$ ). The control software would have to be modified as above. To use the system, a caller selects any trunk to use the cerrestrial network. Using the call address, the Earth station interface will recognize that it is a terrestrial call and pass it directly to the local central office. To access the satellite network, the caller must select one of the trunks that pass through the ACTS interface and dial a single-digit satellite access code, followed by the normal call address digits. The interface will recognize the access code and route the call through the satellite network. This interface has some disadvantages, in that plant communications must be temporarily interrupted in order to set up the interface, and once operational the Earth station interface hardware may have some affect on plant reliability.

The small business office is defined here as an office served by a number of subscriber lines with no switching capability other than that provided by the local CO. This office will be supported where possible by the provision of additional hand sets connected directly to the Earth station interface. A call using the satellite network can then be made by selecting one of these hand sets and dialing the appropriate destination address. 


\section{Category Two Services}

The second category of services includes those services having data rates of $>56 \mathrm{kbit} / \mathrm{sec}$ and $\leq 1.536 \mathrm{Mbit} / \mathrm{sec}$. Category Two services are generally provided by $T 1$ networks using $T 1$ multiplexers. In order to support this category of services, the Earth station interface will be compatible with Tl multiplexing hardware. This hardware typically maintains $T 1$ framing, but may use a nonstandard subframe format. This means that these networks must operate with like hardware at each node. In a ring network, for example, each node in the network is serviced by an identical multiplexer. The muitiplexing hardware drops to a node that portion of the incoming $T 1$ destined for that node, and inserts data destined for other nodes into the outgoing $T I$.

Figure 4 fllustrates some of the Category Two services available when using a PBX and a Tl multiplexer. A wide variety of services are supported by this hardware through the use of commercially avallable plug-in modules. One example of the many service offerings is 768-kbit/sec compressed video. An experimenter can use this service to conduct teleconferences over ACTS. As shown, the sum of the potential inputs to the multiplexer can exceed a single T1. It is the function of the $T 1$ network controller to configure all of the interfaces in the $T 1$ network according to a predetermined priority, so that the sum of the active inputs does not exceed one $\mathrm{Tl}$.

The flexibility of the multiplexing hardware provides compatibility with 4-wire E\&M, foreign exchange, $D X$, and single-frequency signaling for voice, and with RS-232-C/CCITT V.24, V.35, MIL-STO 188-114, and RS-422/423 for data. New hardware, such as 56-kbit/sec FAX and 56-kbit/sec computer terminal modems, can al so be demonstrated.

While all Mode 1 Earth station interfaces will be compatible with the Tl multiplexing hardware, it is expected that few of the experimenter communications plants will include that hardware. Therefore, to properly demonstrate this category of services, at least one pair of $\mathrm{Tl}$ multiplexers and two mobile model "offices" will be avallable for placement on experimenter premises. The telecommunications hardware in these offices will demonstrate the various Category Two services listed above.

\section{Category: Three Services}

The third category of services includes those requiring a data rate of $>1.536 \mathrm{Mbit} / \mathrm{sec}$ up to $44.736 \mathrm{Mbit} / \mathrm{sec}$. Generally, the se services are experimental and will only be supported by a few specialized Earth stations. These services will make use of the latest developments in telecommunications hardware in both the Earth station interface and the communications plant, as well as in the station/plant links. For example, teleconference hardware is avail$a b l e ~ t h a t ~ g e n e r a t e s ~ 3-M b i t / s e c$ (TIC) compressed video. To demonstrate this service, where practical, a few communications plants will be provided with this hardware and Tlc-compatible Earth stations. An appropriate link (possibly optical) between plant and station will also be implemented. Because the NGS at NASA Lewis will be compatible with all three categories of service, a 3-Mbit/sec teleconference can be conducted among the NGS and these specialized stations located at any sites within the ACTS antenna coverage area. The interfaces of these stations will also accommodate data rates up to 
44-Mbit/sec. A T3 multiplexer will form the basis of this and the above interfaces. All "Category One and Two" services will also be offered by these specialized Earth stations (fig. 5).

In addition to the above three service offerings, a limited number of Earth stations will provide Integrated Services Digital Network (ISDN) and packet switching services. ACTS participation in ISDN field trials is planned for both $2 B+D$ and $23 B+D$ protocols. The purpose of this involvement is to demonstrate ACTS compatibility with ISDN (as well as packet switching) hardware and protocols. The terrestrial interface hardware design for these Earth stations is under study and will not be addressed by this paper.

\section{ACTS MODE I COMMUNICATIONS SYSTEM TESTS}

In addition to the services offerings, the interface must also support a variety of communications system tests. ACTS will be thoroughly tested in geosynchronous orbit to evaluate and quantify system and subsystem performance. The NGS will be the primary facility for detalled testing of the various ACTS subsystems. The network of Mode 1 Earth stations and the NGS will provide the mechanism for the verification testing of the ACTS communications system as a whole. The specific functions to be tested include:

Antenna Functions

Beam hopping

Beam coverage

BBP Functions

Demodulation and remodulation Store and forward

Master Control Station Functions

Network control channel operation

Demand assignment algorithm

Burst time plan algorithm

Adaptive rain fade algorithm

Network acquisition process

Synchronization and timing processes

\section{Adjacent Channel Interference}

\section{Co-Channel Channel Interference}

Most of the above functions can be tested statically using only a few stations. However, testing the dynamic operation of the system under normal and near-capacity conditions requires a network of stations and a traffic load that is dynamic and varied in service type. So as not to be reliant only upon the activity within each experimenter communications plant in the network, load generators and link test equipment will be connected to each Earth station (fig. 6). Both the load generators and the link test equipment will be remotely controlled from the NGS at NASA Lewis. 
The load generators have the capacity to create approximately 50 simultaneous and independent originating/terminating calls. Each site can be programmed with specific and different call scenarios and loading rates. Call generation consists of a call sequence beginning with an "off-hook, "followed by the detection of a dial tone, transmission of dial digits, detection of ringing denoting a successful completion of the circuit, a simulated conversation period, and a return to the "on-hook" state. A report of call setup performance is output at specified intervals.

The link test equipment will be used to test the DSI/TI lines and DSO circuits. Included will be the measurement of bit error rate using standard pseudorandom data patterns. The test equipment will also insert errors to evaluate circult error recovery processes.

\section{APPLICABLE SPACE SEGMENT DESIGN REQUIREMENTS}

The interface must also be compatible with those requirements placed on it by the space segment design. Two space segment design characteristics significantly affect the interface design requirements. The first characteristic addresses Earth station total throughput. The throughputs of a typical and of an atypical Earth station are $1.544 \mathrm{Mbit} / \mathrm{sec}$ and $44 \mathrm{Mbit} / \mathrm{sec}$, respectively. This means that the terrestrial interface must connect to the station TDMA and trarismit/receive hardware at $1.544 \mathrm{Mbit} / \mathrm{sec}$ or $44 \mathrm{Mbit} / \mathrm{sec}$ (fig. 1).

The second characteristic addresses the method of spacecraft capacity allocation. All allocations of satellite capacity in the ACTS network are demand assigned. Thus, all of the unused capacity is available as needed to any Earth station in the network. The demand-assignment process begins when traffic appears at an Earth station interface; e.g., an off-hook occurs on a subscriber line or a trunk. That station must then obtain a new circuit(s) in the satelitite network. This is accomplished by the Earth station when it transmits a circuit request message to the master control station (MCS) using the network control channel. Included in the request is the destination Earth station address. The ACTS MCS receives the request, passes call address information on to the destination Earth station, creates the circuit(s) in the satellite network, and assigns the circuit(s) to the source and destination Earth stations.

The volce circuit setup process, including the station capacity request, must be "transparent" to the caller, and must be accomplished at least within the time it takes to set up a call using the terrestrial network. Call setup for volce applications must, therefore, be an automatic, real-time function. This is best accomplished if the Earth station terrestrial interface is capable of performing telephony signaling; i.e., the automatic collection/ generation of call address (dial) digits. The address digits processed at the interface must be available to the Earth station control computer for insertion into the network control channel. This requires a communication link between the interface hardware and the station control computer, (fig. 1).

Trunk circuit setup need not be automatic or real-time (an automatic set up process is being considered). Requests can be made manially by an Earth station operator using the control computer terminal display. The operator 
enters the number of circuits (up to 672 64-kbit/sec circuits) and their destination, and the station control computer inserts them into the network control channel. This is a relatively simple interface with little or no telephony signaling.

The above interface design requirements apply in general to both the network Earth stations and the NGS. However, because the NGS will be permanently. located at NASA Lewis, its interface need only be compatible with NASA Lewis communications plant. Furthermore, because the NGS will be the primary ACTS test facility, the total throughput capability of the NGS interface is in excess of $44 \mathrm{Mbit} / \mathrm{sec}$.

\section{EARTH STATION TERRESTRIAL INTERFACE SPECIFICATIONS}

The terrestrial interface hardware specifications are determined by the requirements discussed above. In summary, those requirements are:

(1) The hardware must easily interface to PBX's, key systems, multiple subscriber lines, and Tl multiplexers.

(2) The hardware must accommodate a wide variety of telecommunications services, including voice, video, and data.

(3) The interface must support real-time demand assignment.

(4) The hardware must accommodate terrestrial network test equipment.

(5) The hardware must provide a T1 or a T3 interface as a standard interface to the Earth station plesiochronous buffers.

(6) The hardware must provide an RS-232 or equivalent) interface to the control computer.

Requirements 1 and 2 suggest the need for a modular design with plug-ins for each plant and service type. Requirement 1 also requires that the interface isupport several terrestrial trunk protocols, including associated supervisory signaling functions. Requirement 2 also requires that the interface perform the functions of a subscriber loop interface. These include battery feed, overvoltage protection, ringing, supervision, coding, hybrid, and testing (BORSCHT). Requirement 3 requires that the interface perform the address signaling function, 1.e., address digit collection/transmission. Requirement 5 sizes the interface. Requirement 6 requires that the interface be remotely controllable.

All of the functions specified by the above requirements for services using rates less than or equal to $\mathrm{Tl}$ ( $\mathrm{i} . \mathrm{e}$. , categories one and two, could be provided by standard telephone company central office hardware). This hardware typically provides services for 10000 subscribers or more and fills a small bullding. Size and expense makes impractical its use as an Earth station interface. Specialized central office hardware, however, has been identified that is small and modular in design with one unit capable of accommodating up to 56 ports; e.g., subscriber lines. The exact capacity of each unit is a function of its specific plug-in configuration. This small central office is 
sized to be mounted in a standard 19-in. EIA Relay Rack. Figure 7 illustrates this hardware configured to provide category one and two services. As configured in figure 7 , it will serve 24 telephone circuits, 2 Tls, and 4 RS 232 ports.

Figure 8 illustrates the use of the small central office as the terrestrial interface between the Earth station TI/Pleslochronous buffers and the telephony I/O. The telephony I/O consists of category one telephony hardware and communication test hardware connected directly to the small central office and category two telephony hardware connected through a digital Tl multiplexer to the central office ( $f i g .8$ ). With this complement of interface hardware and appropriate plug-ins a small Earth station will be able to provide category one and two services to experimenter plants having PBX's, key systems, and individual subscriber lines. It is this interface configuration that will most likely be modified to accommodate ISDN and packet switched operations.

The requirement to provide category three services and therefore rates up to T3 will be accommodated by the larger Earth stations only. In this case a small central office integrated with a digital T3 multiplexer will provide the terrestrial interface between the Earth station T3/Plesiochronous buffers and the telephony $1 / 0$. The small central office and the Tl multiplexer are both connected directly to the T3 multiplexer by a Tl (fig. 9). Category one an two services hardware connects as appropriate to the central office or the $\mathrm{Tl}$ multiplexer. With this complement of interface hardware and appropriate plugins a large Earth station will be able to provide category one, two and three services to experimenter plants having PBX's, key systems, and individual subscriber lines and to specialized high data rate devices.

Figure 10 shows the configuration of the terrestrial input/output hardware that will enable the NGS to operate essentially as a Category Three Earth station. The difference is primarily a result of the high throughput capability of the NGS. The NGS can transmit and receive through 12 ports at $1.544 \mathrm{Mbit} /$ $\mathrm{sec}$, and through 8 ports at $6 \mathrm{Mbit} / \mathrm{sec}$. The trunk connecicion to NASA Lewis PBX gives all of NASA Lewis telephony hardware access to the ACTS communications system. Category Two and Three hardware and services will be located in a "model business office" within the NGS complex. This office will be linked through the NGS to the other Category Three Earth stations in the ACTS Mode 1 network. The control terminals used to operate the terrestrial hardware in the network (e.g., Tl network multiplexers and link test hardware) will be located in the MCS area.

\section{SUMMARY}

A network of Earth stations will be provided for use in demonstrating ACTS compatibility with today's and tomorrow's telecommunications services. The ACTS network Earth station terrestrial interface hardware will be sufficiently flexible to accommodate a wide variety of communication plants. Full mesh connectivity using demand assignment protocols will be provided between all Earth stations. Earth station maximum throughput will be either one $\mathrm{Tl}$ or one T3. 
TABLE I. - SERVICE OFFERINGS AND INTERFACE HARDWARE BY SERVICE CATEGORY

\begin{tabular}{|c|c|c|c|c|}
\hline $\begin{array}{r}\text { Service } \\
\text { category }\end{array}$ & $\begin{array}{l}\text { Earth station } \\
\text { interface } \\
\text { hardware }\end{array}$ & $\begin{array}{l}\text { Terrestrial } \\
\text { interface } \\
\text { hardware }\end{array}$ & $\begin{array}{l}\text { Maximum } \\
\text { data rates }\end{array}$ & Applications \\
\hline \multirow[t]{3}{*}{$\begin{array}{c}\text { Category } \\
\text { One }\end{array}$} & \multirow[t]{3}{*}{ Central office } & $\begin{array}{l}\text { Applications } \\
\text { hardware } \\
\text { connects } \\
\text { directly to } \\
\text { central } \\
\text { office }\end{array}$ & \multirow{3}{*}{$\begin{array}{c}56 \text { kbps } \\
\text { data }\end{array}$} & $\begin{array}{l}\text { Telephones. } \\
\text { Facsimite } \\
\text { Electronic mail }\end{array}$ \\
\hline & & $\begin{array}{l}\text { Private branch } \\
\text { exchange } \\
\text { (PBX) }\end{array}$ & & Main frame computers \\
\hline & & Key system & & \\
\hline $\begin{array}{c}\text { Category } \\
\text { Two }\end{array}$ & $\begin{array}{l}\text { Central office } \\
\text { Tl Multiplexer }\end{array}$ & Tl Multiplexer & 1.536 Mbps & $\begin{array}{l}\text { Host computers } \\
\text { Compressed video }\end{array}$ \\
\hline $\begin{array}{l}\text { Category } \\
\text { Three }\end{array}$ & $\begin{array}{l}\text { Central office } \\
\text { T1 Multiplexer } \\
\text { T3 Multiplexer }\end{array}$ & $\begin{array}{l}\text { Nonstandard } \\
\text { hardware }\end{array}$ & 44 Mbps & $\begin{array}{l}\text { Main frame computer } \\
\text { to main frame } \\
\text { computer data } \\
\text { transfer } \\
\text { High resolution video }\end{array}$ \\
\hline
\end{tabular}

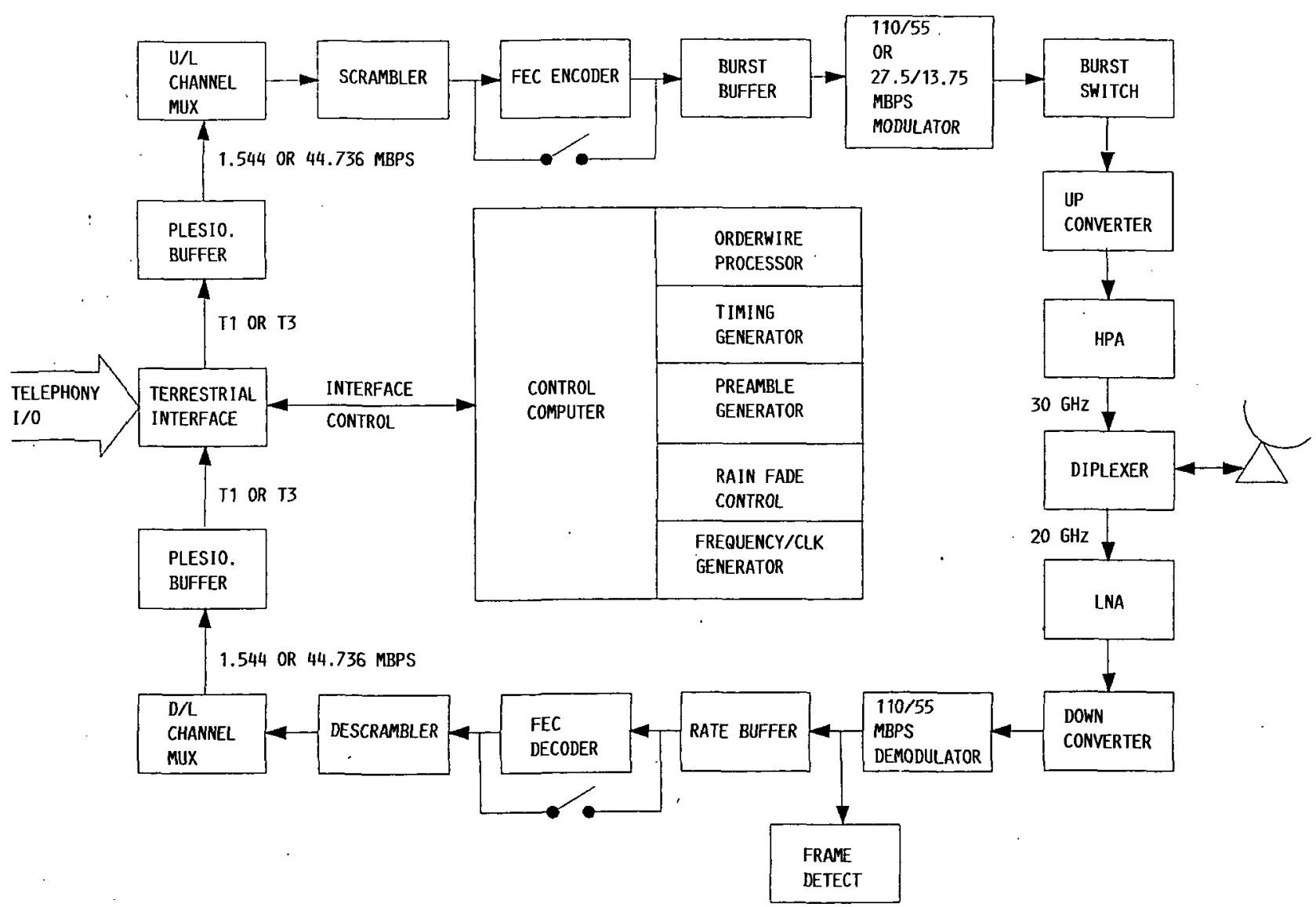

FIGURE 1. - A FUNCTIONAL BLOCK DIAGRAM OF AN ACTS MODE 1 EARTH STATION. 


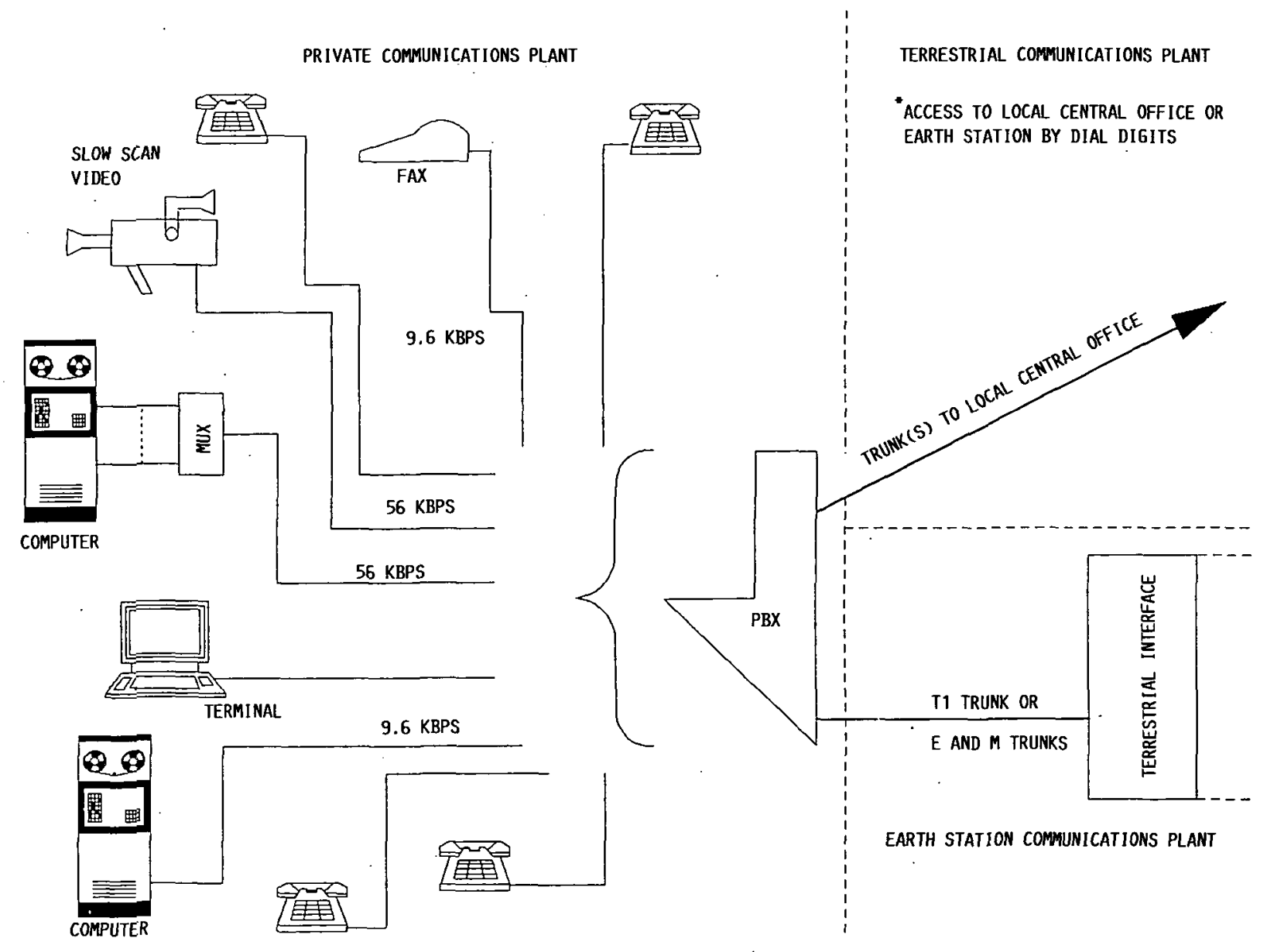

Figure 2. - CATEgORY ONE SERVICES USING A PRIVATE BRANCH EXCHANGE (PBX). 


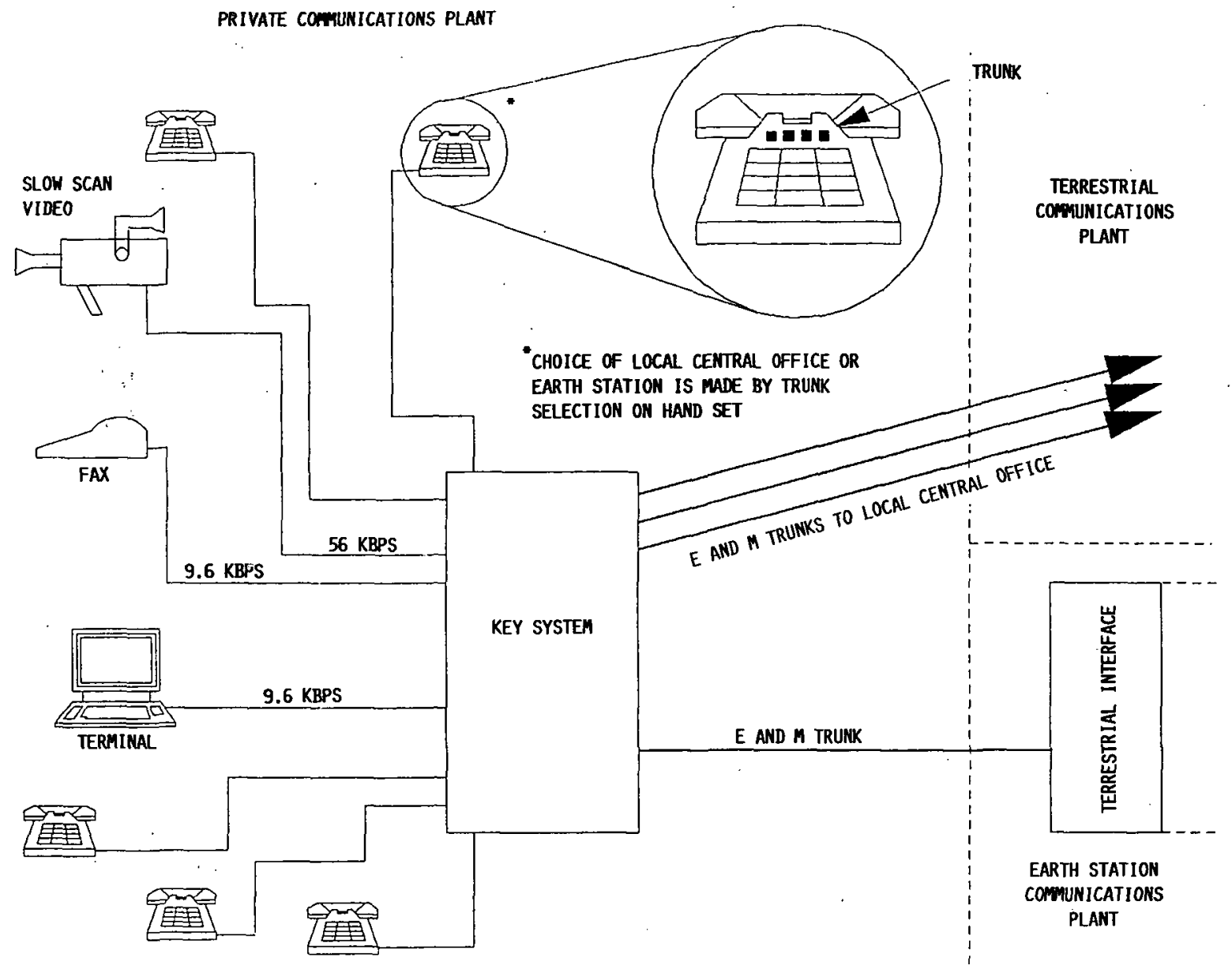

FIGURE 3A. - CATEGORY ONE SERVICES USING A KEY SYSTEM (OPIION 1). 


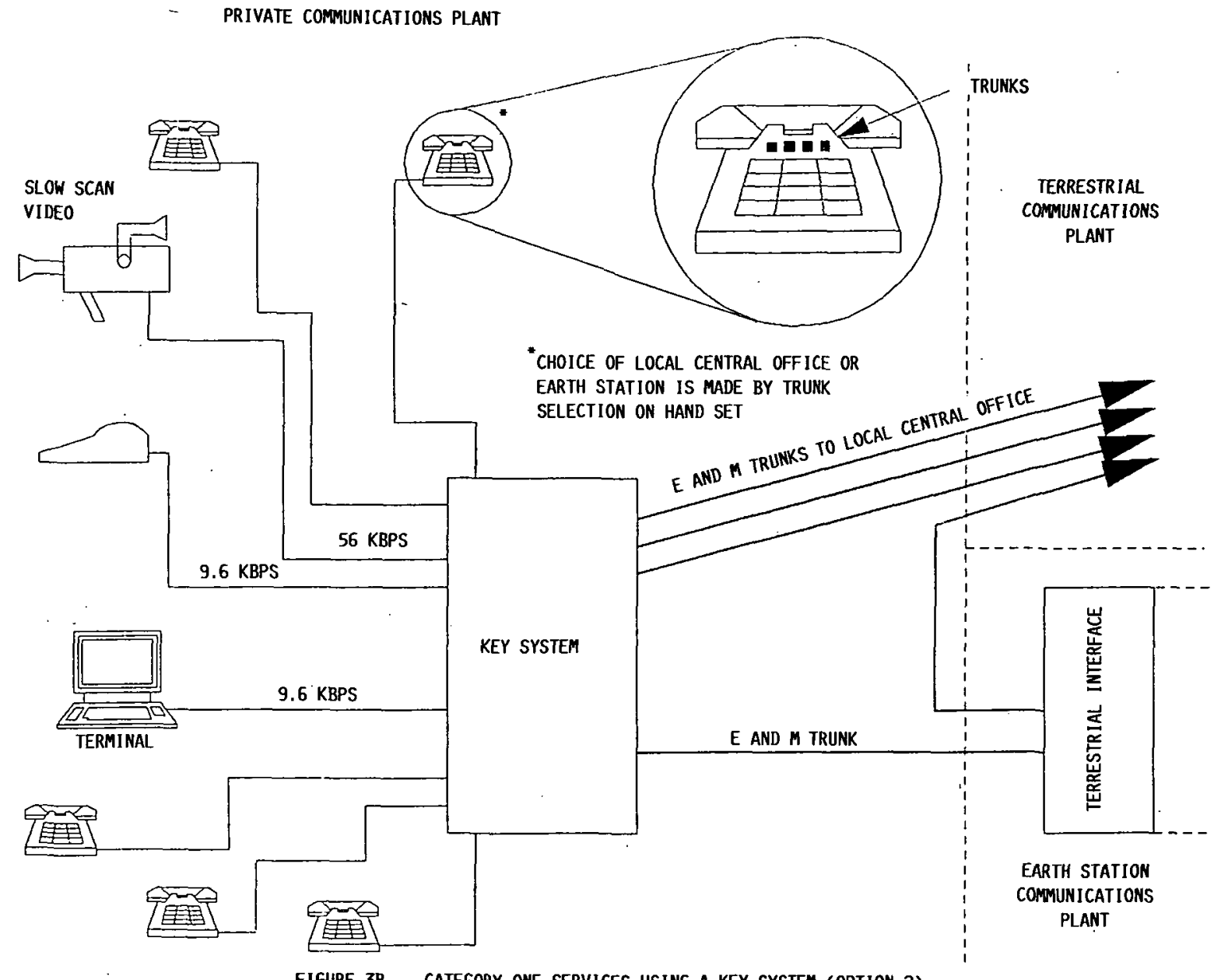

FIGURE 3B. - CATEGORY ONE SERVICES USING A KEY SYSTEM (OPTION 2). 


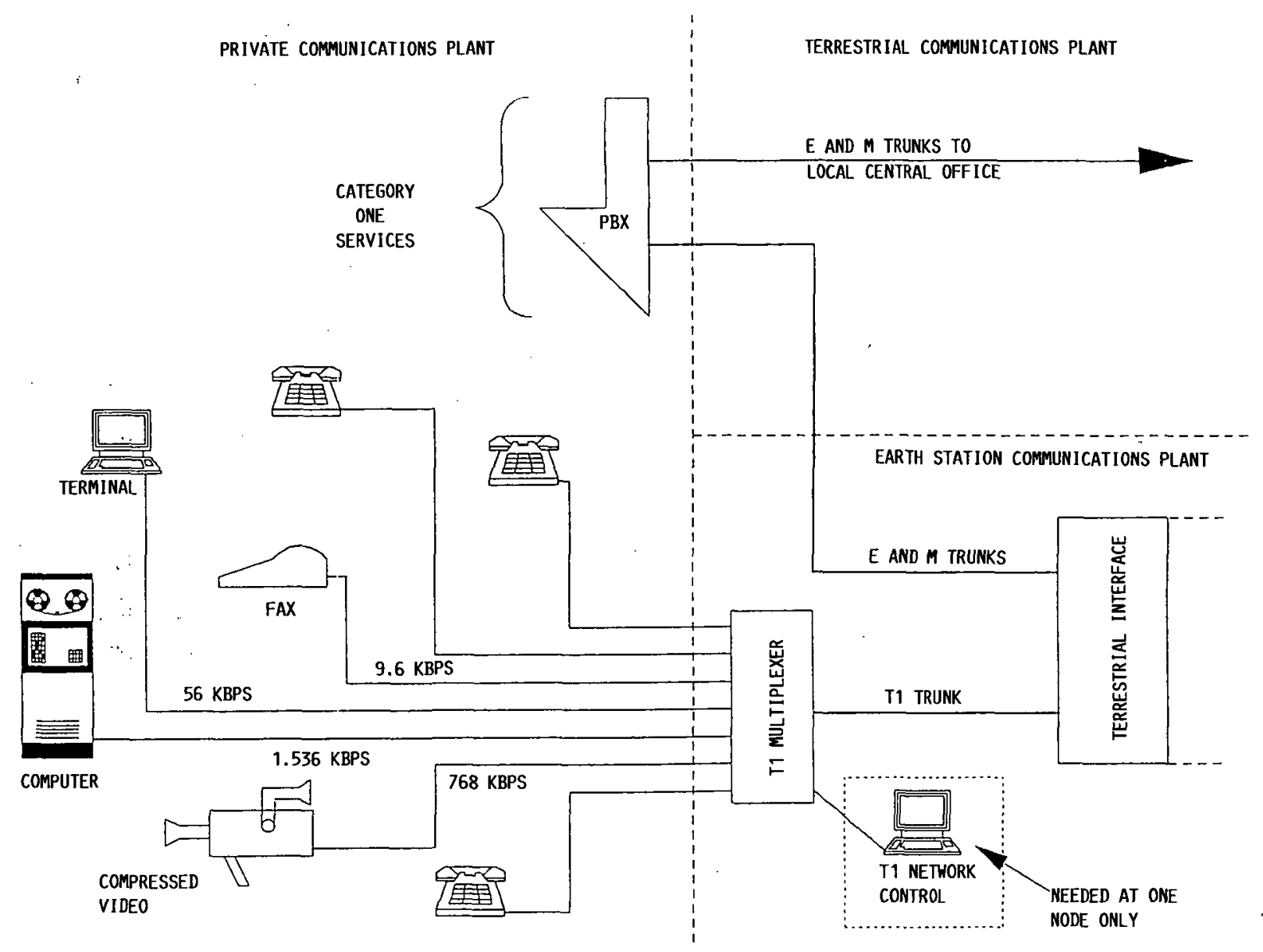

FIgURE 4. - CATEgORY TWO SERVICES USING A PBX AND A T1 MULTIPLEXER. 


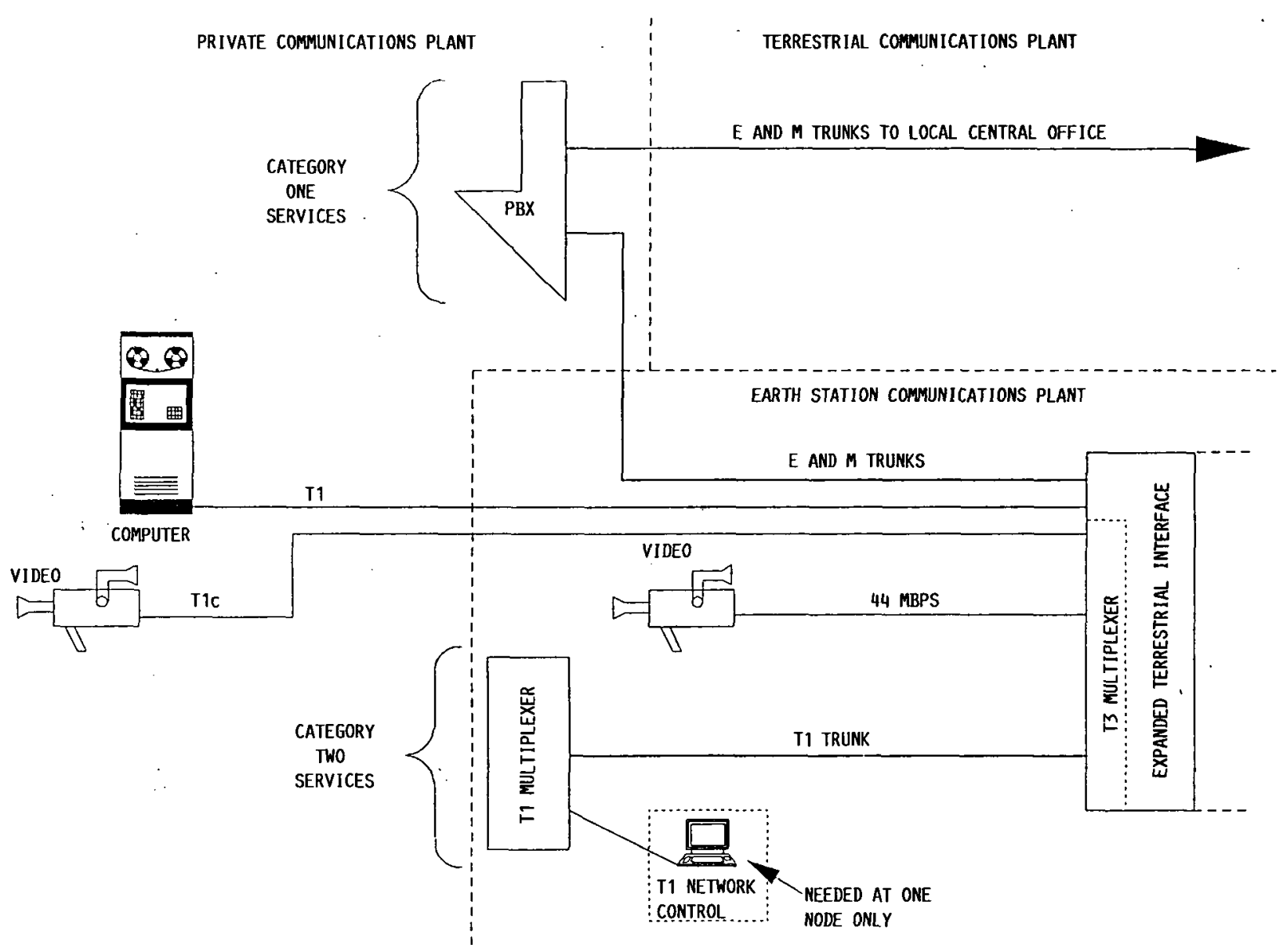

FIgURE 5. - CATEgORY THREE SERVICES USING A PBX, A T1 MULTIPLEXER AND A T3 MULTIPLEXER, 


\section{ORIGINAL PAGE IS \\ OF POOR QUALITY}

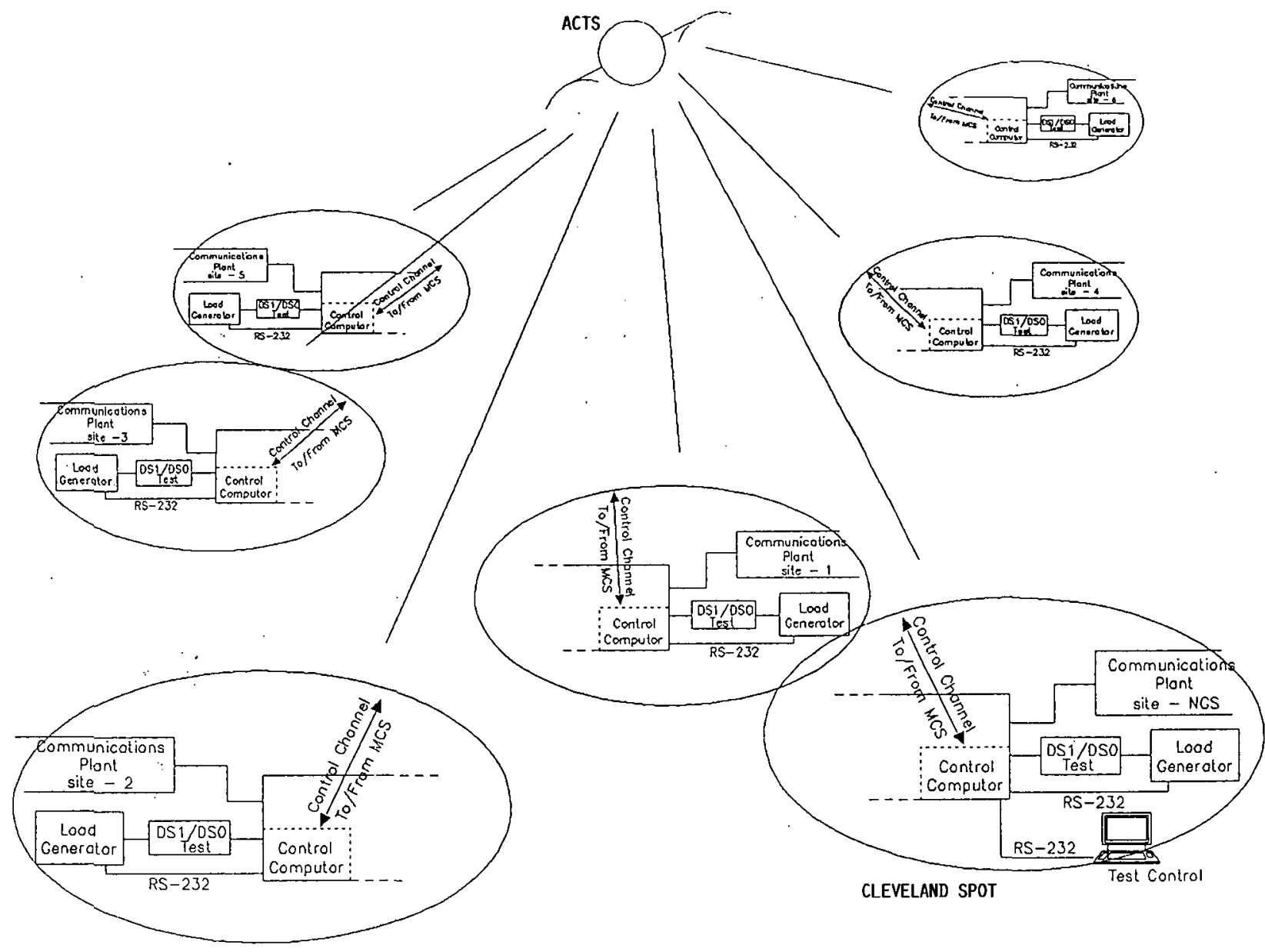

FIGURE 6. - HARDWARE CONFIGURATION FOR COMMUNICATIONS SYSTEM TEST. 
SAMPLE CAPACITY:

24 LINE CIRCUITS (TELEPHONE (IRCUITS)

$2 \mathrm{~T}$ is

4 RS 232 PORTS

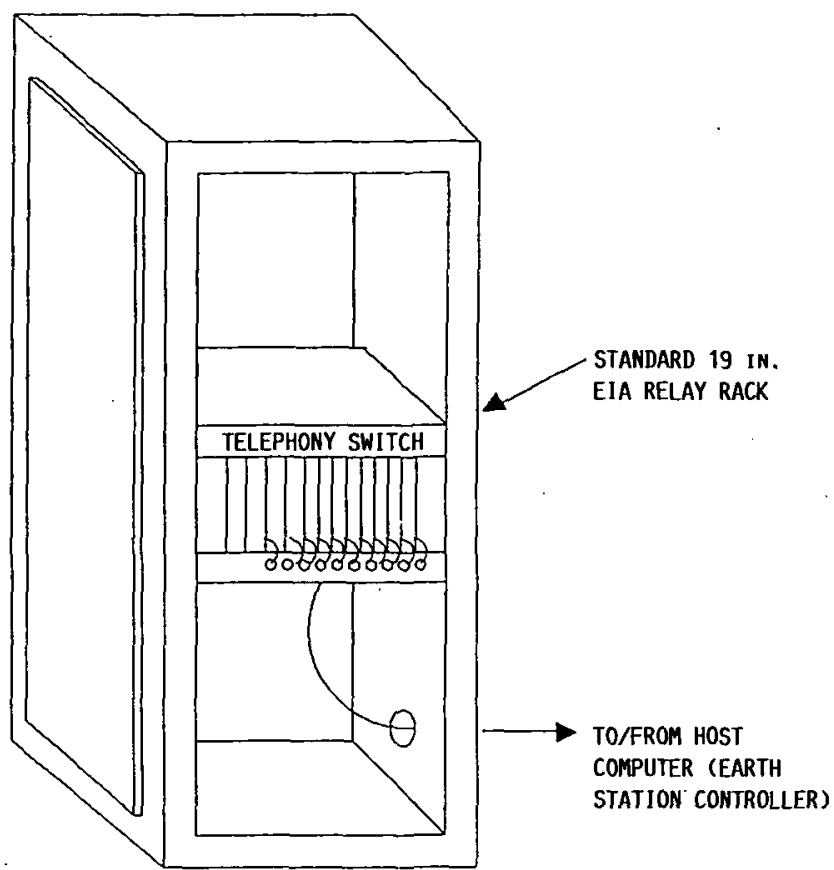

FIGURE 7. - SMALL CENTRAL OFFICE CONSISTS OF A PROCESSOR AND A CIRCUIT SWITCH FOR VOICE AND DATA. IT ALSO PERFORMS VOICE AND DATA SIGNALING FUNCTION. 


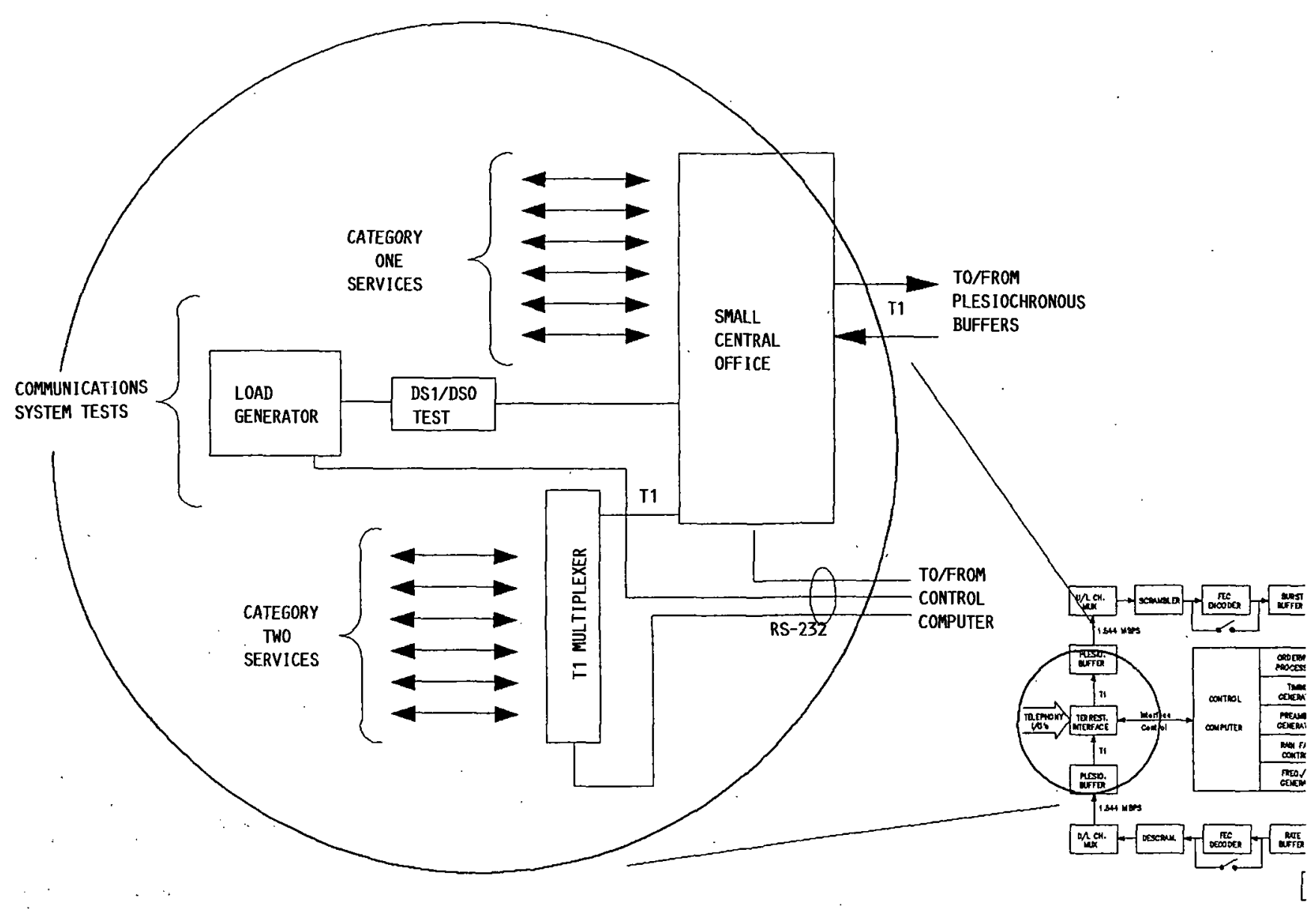

Figure 1. - A functional block diogrom of or FIGURE 8. - CENTRAL OFFICE AND TELEPHONY HARDMARE CONFIGURATION FOR CATEGORY ONE AND TWO SERVICES AND COMUUNICATIONS SYSTEM TESTS. 


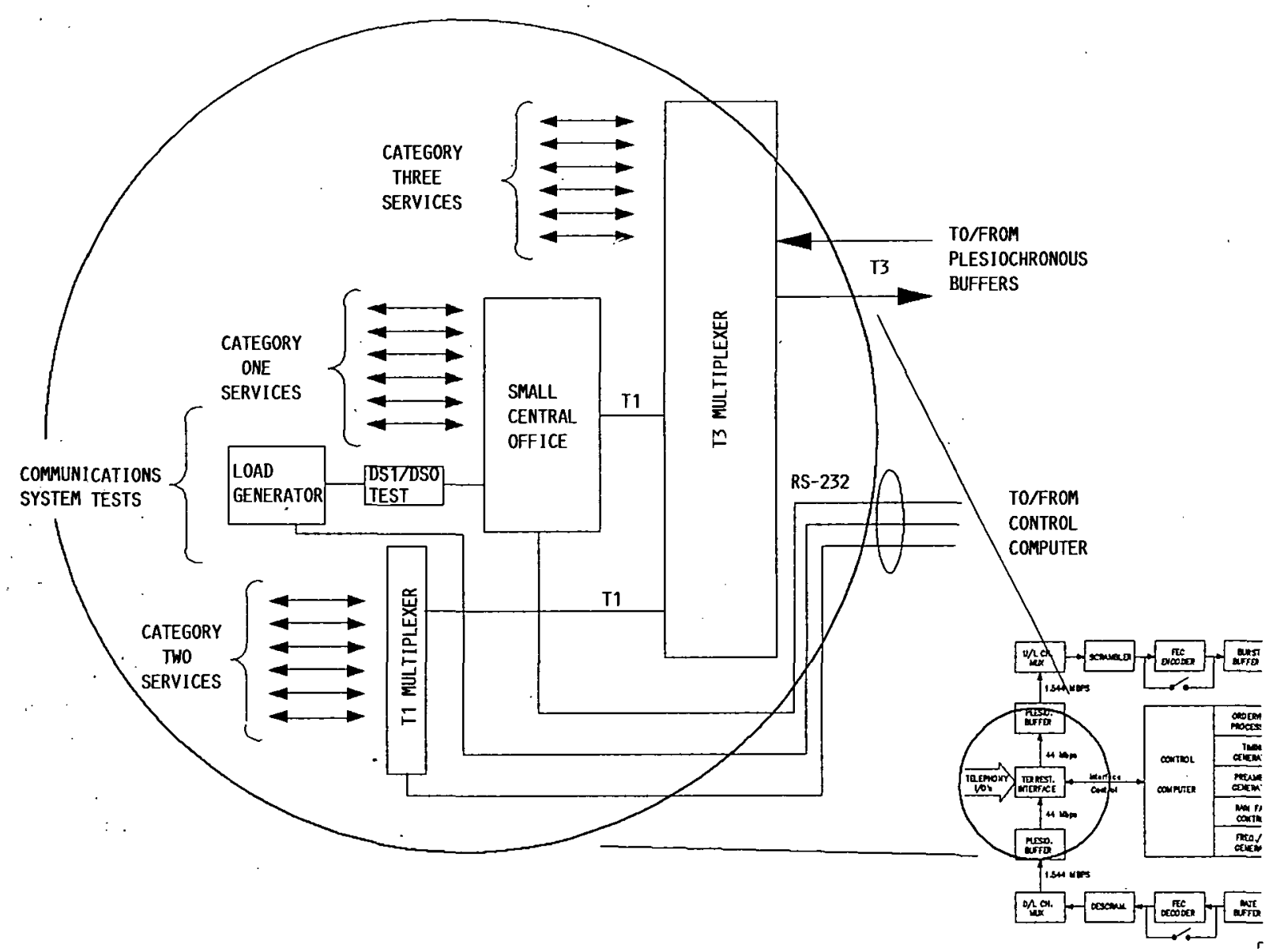

FIGURE 9. - CENTRAL OFFICE AND TELEPHONY HARDWARE CONFIGURATION FOR CATEGORY ONE, TWO, AND THREE SERVICES AND COMMUNICATIONS SYSTEM TESTS.

ORIGLAAL PAGE IS

OF POOR QUALITY 


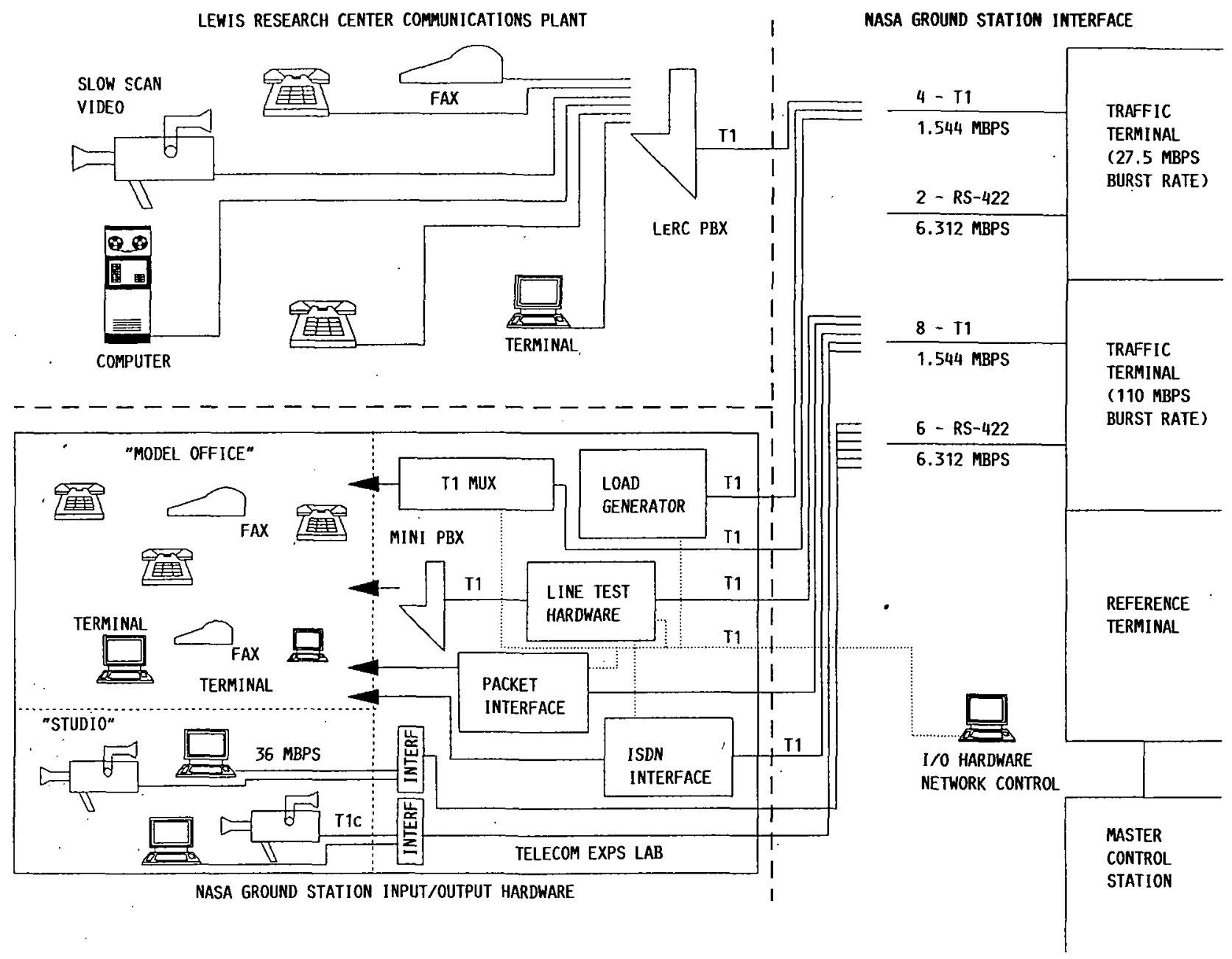

FIGURE 10. - MASA GROUND STATION INPUT/OUTPUT HARDHARE COMFIGURATION. 


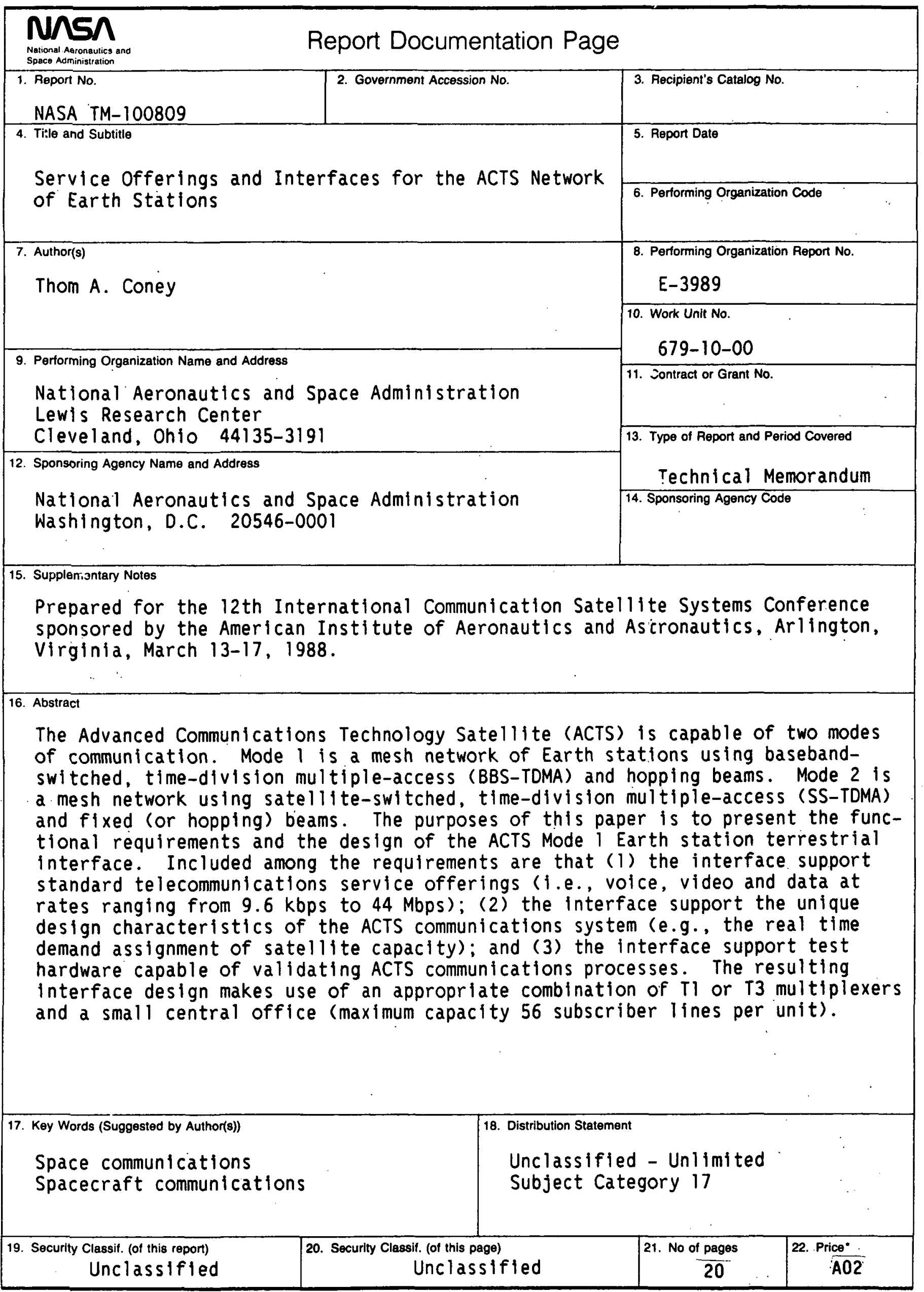


National Aeronautics and

Space Administration

\section{Lewis Research Center}

Cleveland, Ohio 44135

Oricial Bustness

Penaly for Private Use \$300
ADDRESS CORRECTION REQUESTED

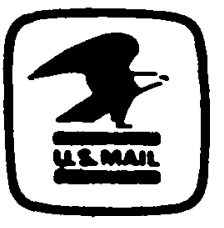

Postage and Fees Paid National Aeronautics and Space Administration NASA-451 